\title{
Vestibular and radiological evaluation of hearing impaired children with delayed Motor development
}

\author{
Original \\ Mohamed Elmoursy', Mohamed Salama Bakr', Samy Abdelaziz Sayed ${ }^{3}$, Mostafa Ahmed \\ Article \\ Ali $^{4}$ and Enass Sayed Mohamed ${ }^{1}$
}

${ }^{1}$ ENT Department, Al-Azher university, Assuit, ${ }^{2} E N T$ Department, Assuit university,

${ }^{3}$ Radiology Deptartment, Assiut University Hospital, ${ }^{4}$ Audiovestibular medicine Unit, Sohag

University Hospital, Egypt.

\begin{abstract}
Background: Combined hearing and vestibular loss in children pose potentially significant problems. Children and infants with vestibular problems are faced with motor problems that could limit their normal development.

Objectives: the aim of the study is to assess the relationship between the vestibular disorders and the delayed motor development in hearing impaired children as well as to assess the integrity of the vestibular system through clinical testing and radiological imaging in those children with delayed motor development.

Methods: Thirty hearing impaired children with history of delayed motor milestones, and a control group of 10 hearing impaired children with normal motor development were included with variable degree of hearing loss. Each child was subjected to careful history taking, general examination, otoscopic examination, motor and balance questionnaires were answered by the parents or caregivers, audiological evaluation either through conditioned play audiometry or conventional audiometry, speech audiometry and Immittancemetry. Vestibular evaluation through cVEMP and caloric tests and finally the radiological studies through CT and MRI of the petrous bone.

Results: There were variable degrees of hearing loss among both groups. In the control group (10 HI children, 20 ears), 18 ears $(90 \%)$ had VEMP response, while two ears (10\%) had absent VEMP, while in the study group (30 HI children, 60 ears), 48 ears (80\%) had VEMP response, while 12 ears (20\%) had absent VEMP. All children in the control group had normal caloric response, while in the study group, 23 children (77\%) had normal response, and seven children (23\%) had abnormal caloric response, 4 children had bilateral weakness and 3 had unilateral weakness. CT and MRI study of petrous bone was done for the control group and revealed normal radiology, while in the study group, 21 children had normal imaging $(70 \%)$ and the last 9 children $(30 \%)$ had abnormal findings, the most common abnormalities was enlarged vestibular aqueduct (13\%), followed by common cavity $(7 \%)$.

Conclusion: Children with hearing loss, irrespective of the degree of hearing loss, the vestibular system should be screened, assessed as it may be responsible for co-morbidities in fine and gross motor difficulties. Early intervention and effective therapy will be the proper way to get good outcome.
\end{abstract}

Key Words: delayed motor function, hearing impaired children, radiological evaluation, vestibular.

Received: 28 June 2018, Accepted: 17 May 2019

Corresponding Author: Mohamed M. Elmoursy, MD, Audiovestibular medicine Unit, Al-Azher University Hospital, Assiut, Egypt, Tel.: +2 01003615648, E-mail: moursy_audio2020@yahoo.com

ISSN: 2090-0740, July 2019 Vol.20, No.2

\section{INTRODUCTION:}

Disturbances in cochlear function, which can result in sensorineural hearing loss (SNHL), could accompany vestibular impairment because the cochlea and the vestibule share the continuous membranous labyrinth of the inner ear, therefore, injury or trauma prenatally, perinatally, or postnatally may cause damage to one or both systems ${ }^{[1,2]}$.

Combined hearing and vestibular loss in a child poses potentially significant problems, even though this combined loss might only be expressed in subtle disturbances of normal development ${ }^{[3]}$. Children and infants with vestibular problems are faced with motor incoordination and locomotor problems that could limit normal development ${ }^{[4]}$.

The high incidence of vestibular dysfunction in children with hearing loss likely reflects the anatomical, histologic, and physiologic similarities between the cochlear and vestibular end organs ${ }^{[5]}$. Balance disorders in children are relatively common, but largely unrecognized as young children are often unable to describe these different perceptions, and thus, any complaint of dizziness, instability, or vertigo should be considered in the broad context of the 'dizzy child' for diagnostic purposes ${ }^{[6,7]}$.

Vertigo in children differs from that in adults, because of 
three main reasons: Firstly, vestibular disorders are often ignored in children, because vertiginous manifestations are usually attributed to lack of coordination or behavioral problems ${ }^{[8]}$. Secondly, as children often lack the communication ability to describe accurately their symptoms, diagnosis is based less in history and much more in clinical examination and laboratory investigations. Finally, although most diseases that cause vertigo in adulthood occur in childhood as well, their frequency may be different, depending on the age of the patient. A typical example is benign paroxysmal positional vertigo (BPPV), which is the most common peripheral vestibular disorder in adults, but less frequently occurred in children ${ }^{[9]}$.

An understanding of motor development and postural responses in the growing child is therefore necessary in order to appropriately evaluate vestibular function at various stages of the child's development. Although the vestibular system is fully structurally developed at birth, balance responses continue to mature and, therefore, results elicited upon testing will depend upon the developmental age of the child. This is especially important in the evaluation of the premature infant ${ }^{[10]}$.

Documentation of vestibular dysfunction in children with hearing impairment has a long and rich history which has indicated that somewhere in the range of 20 to $85 \%$ of children with hearing loss demonstrate some form of vestibular end organ dysfunction ${ }^{[11,12,13]}$.

Vertigo in children is a diagnostic challenge for clinicians because of their immature peripheral and central vestibular systems and limited communication abilities $^{[14-15]}$. Vertigo in children, as in adults, is often divided into peripheral and central causes. Peripheral causes include otitis media related vertigo, BPVoC, Meniere's disease, posttraumatic vertigo, perilymphatic fistula, vestibular neuronitis, and labyrinthitis ${ }^{[15,16]}$. The most common central causes of vertigo or dizziness are epilepsy, migraine, multiple sclerosis, and tumors of the central nervous system $(\mathrm{CNS})^{[17]}$.

The assessment of the vestibular system in children is an important part of the medical evaluation whenever hearing loss and/or dizziness are reported during the case history ${ }^{[18]}$. There are several convincing reasons to assess a child's vestibular function. First, determining the integrity of the vestibular system can help physicians to diagnose the impairment and define the most appropriate course of treatment. Second, for those children with dizziness/ vertigo who have serious health problems, the vestibular system assessment can help identify patients whose dizziness/vertigo stems from a significant neurological impairment ${ }^{[18]}$.

Pediatric vestibular testing can be accomplished if the testing environment is adapted to the special needs of very young children. This requires relatively few modifications to the standard test environment.

\section{AIM OF THE WORK:}

To assess the relationship between vestibular disorders and delayed motor development in hearing impaired children.

Also to assess the integrity of the vestibular system through clinical testing and radiological imaging in hearing impaired children with delayed motor development.

\section{Subjects:}

Two groups of children attended to the Audio vestibular medicine unit of Assiut University Hospital, during the period between March 2014 to July 2017.

Study group: Thirty children with SNHL of varying degree and referred to audio vestibular unit for hearing assessment or follow up and they had history of delayed motor development.

Control group: Ten children, their age and sex distribution matched with the study group. All have SNHL and with history of normal motor development.

Consent was taken from the parents or caregivers of the children that participate in this study.

Inclusion criteria

- Age: from four to ten years old children.

- Sex: both male and female.

Exclusion criteria

- Children with conductive hearing loss were ruled out as it impedes the VEMP test.

- Acquired causes of cochleovestibular insults like ototoxicity and meningitis also were excluded.

- Children with problem in the neck musculature or scars were excluded as it may interfere with VEMP tests.

\section{Equipment:}

1. Sound-treated room, Industrial Acoustic Company, model IAC 1602 A-CT, USA.

2. Two channel pure tone audiometer, model Orbiter 922 Version 2.

3. Single frequency tympanometry with probe tone 226 HZ, Immittancemetry, model AZ26. 
4. VEMP testing using the Eclipse platform, Interacoustic; Denmark.

5. Electronystagmography (ENG), Micromedical windows two channel ENG, Meta4, version 8.R.1.

6. VNG Micromedical mobileye2 channel spirit.

\section{Methodology}

* Complete history taking from the parents including prenatal, natal, postnatal history, developmental history, timing and course of hearing loss, consanguinity and family history of hearing loss, history of head trauma, and vestibular complaints.

* General and neurological evaluation was done.

* ENT and otological examination was done.

\section{Questionnaires:}

The questionnaires were developed in the light and the help of previously validated questionnaires by Shabana et al, 2012 $2^{[7]}$ and Youssif et al 2012 $2^{[19]}$. There were two forms of questionnaires: one of them was the motor and asking about if there was delay in motor function and the age for acquisition of the different motor milestones. The second was the balance questionnaire and it consisted of three parts, answering the first part positively will lead to second and so on. There were presented in Arabic version to the parents or caregivers.

* Audiological evaluation in the form of

A. Conditioned play audiometry or conventional audiometry according to the age and reliability of the children to assess the hearing threshold for both air conduction in the frequencies $250-8000 \mathrm{~Hz}$.and bone conduction threshold in the frequencies $500-4000 \mathrm{~Hz}$.

B. Speech audiometry including the speech reception threshold, using the Arabic spondee words for children ${ }^{[20]}$ and speech recognition score using the Arabic kindergarten phonetically balanced wards ${ }^{[21]}$.

C. Immittancemetry: including tympanometry and acoustic reflexes to assess the condition of the middle ear.

* Vestibular evaluation in the form of:

* cVEMP (vestibular Evoked Myogenic Potential) to assess Saccular Function and inferior vestibular nerve.
* Caloric test was done for assessment of the lateral semicircular canal function.

* Radiological investigations of the inner ears:

CT scan and MRI were done after detailed explanation of the procedure to the parents or caregivers with emphasis on the importance of imaging in evaluating children with SNHL.

Pre-coded data of the present study was entered on computer using Microsoft Excel Software program 2010 for windows. Statistical presentation and analysis was conducted using the range, mean, slandered deviation for quantitative data, numbers and percent's for qualitative data, chi square test, Fisher exact test, Mann-Whitney test, linear correlation coefficient and Spearman correlation. $P$ value $\leq 0.05$ was considered significant. All statistical analyses were performed using SPSS 16.0 (SPSS Software, Chicago, IL).

\section{RESULTS:}

Table 1: comparison between the age and sex distributions of the two groups

\begin{tabular}{|c|c|c|c|c|c|}
\hline & \multicolumn{2}{|c|}{ Patients $(\mathrm{n}=30)$} & \multicolumn{2}{|c|}{ Control $(n=10)$} & \multirow{2}{*}{$P$-value } \\
\hline & No. & $\%$ & No. & $\%$ & \\
\hline \multicolumn{6}{|l|}{ Sex: } \\
\hline Male & 18 & 60.0 & 5 & 50.0 & 0.717 \\
\hline Female & 12 & 40.0 & 5 & 50.0 & \\
\hline \multicolumn{6}{|c|}{ Age*: (months) } \\
\hline Mean \pm SD & \multicolumn{2}{|c|}{$8.02 \pm 1.84$} & \multicolumn{2}{|c|}{$7.35 \pm 2.00$} & 0.357 \\
\hline Range & \multicolumn{2}{|c|}{$4.5-10.0$} & \multicolumn{2}{|c|}{$4.0-10.0$} & \\
\hline
\end{tabular}

Table 2: data of the balance questionnaire

\begin{tabular}{lcc}
\hline & No. $(\mathrm{n}=30)$ & $\%$ \\
\hline Difficulty in walking & 24 & 80.0 \\
Vertigo & 6 & 20.0 \\
Poor balance & 18 & 60.0 \\
Frequent falls & 21 & 70.0 \\
Fear panic & 7 & 23.3 \\
Nystagmus & 5 & 16.7 \\
Interference with daily activities & 6 & 20.0 \\
Difficult reading & 6 & 20.0 \\
Difficulty walking in low & 4 & 13.3 \\
light or dark room & & \\
Becomes upset when feet & 1 & 3.3 \\
leave the ground & & \\
Frequent motion sickness & 4 & 13.3 \\
Sensation of ringing in ears & 3 & 0.0 \\
Avoids playground equipment & 0 & \\
\hline
\end{tabular}


Table 3: Comparison between the age of acquisition of Motor milestones (months) of both groups

\begin{tabular}{|c|c|c|c|c|}
\hline Motor milestone (Study group) & Age in months Mean $\pm \mathrm{SD}$ & Range & Normal age* & P-value \\
\hline Head support & $6.77 \pm 1.17$ & $5.0-10.0$ & $2-3$ & $0.001 *$ \\
\hline Sitting supported & $9.17 \pm 1.34$ & $7.0-12.0$ & 4 & $0.001 *$ \\
\hline Sitting alone & $11.43 \pm 1.89$ & $8.0-16.0$ & 6 & $0.001 *$ \\
\hline Standing Supported & $14.30 \pm 1.84$ & $11.0-18.0$ & 9 & $0.002 *$ \\
\hline Standing alone & $17.03 \pm 1.99$ & $12.0-22.0$ & 12 & $0.001 *$ \\
\hline Walking support & $20.30 \pm 2.04$ & $17.0-25.0$ & 15 & $0.003 *$ \\
\hline Walking alone & $25.13 \pm 2.58$ & $22.0-30.0$ & 18 & $0.002 *$ \\
\hline
\end{tabular}

* Long \& Toscano 2002 (22); McCarthy 2006(23)

The normal age for acquisitions of motor milestones were put by Long \& Toscano 2002; McCarthy 2006, and all children in the control group had normal motor development.

\section{Basic audiological evaluation:}

There were variable degrees of hearing loss among both groups. Hearing loss was classified into mild, moderate, moderately sever, severe and profound HL. Mild hearing loss (26-40 dB HL), moderate HL (41-55 dB HL), moderately severe (56-70 dB HL), severe (71-90 dB HL) and profound $\mathrm{HL}$ (more than $91 \mathrm{~dB} \mathrm{HL})^{[24]}$.

Table 4: comparison between the degrees of hearing loss per ears in both groups

\begin{tabular}{lccccc}
\hline \multirow{2}{*}{$\begin{array}{l}\text { Degree of } \\
\text { hearing loss }\end{array}$} & \multicolumn{2}{l}{ Study $(\mathrm{n}=60)$} & \multicolumn{2}{l}{ Control $(\mathrm{n}=20)$} & \multirow{2}{*}{ P-value } \\
\cline { 2 - 5 } & No. & $\%$ & No. & $\%$ & \\
\hline Mild & 0 & 0.0 & 3 & 15.0 & $0.014^{*}$ \\
Moderate & 7 & 11.7 & 11 & 55.0 & $0.000^{*}$ \\
Moderately severe & 14 & 23.3 & 1 & 5.0 & 0.099 \\
Severe & 13 & 21.7 & 4 & 20.0 & 0.875 \\
Profound & 26 & 43.3 & 1 & 5.0 & $0.002^{*}$ \\
\hline
\end{tabular}

The profound degree was the most frequent in the study group represent $43 \%$ while the moderate degree was the most frequent in the control group $55 \%$. There were statistically significant differences for the mild, moderate and profound degree of hearing loss among both groups.

\section{Vestibular assessment}

\section{VEMP TEST:}

VEMP test was done for both groups;

- In the study group (30 children, 60 ears), 48 ears $(80 \%)$ had VEMP response, while 12 ears $(20 \%)$ had absent VEMP.

- In the control group (10 children, 20 ears) 18 ears $(90 \%)$ had VEMP, while two ears $(10 \%)$ had absent VEMP.
Table 5: VEMP responses in both groups

\begin{tabular}{lll}
\hline VEMP & Study group $(\mathrm{n}=60$ ears $)$ & Control (20 ears) \\
\hline Response & $48(80 \%)$ & $18(90 \%)$ \\
No response & $12(20 \%)$ & $2(10 \%)$ \\
\hline
\end{tabular}

Table 6: Comparison of VEMP latencies P1, N1 and amplitude in right ear for both groups

\begin{tabular}{lccc}
\hline & Study $(\mathrm{n}=30)$ & Control $(\mathrm{n}=10)$ & P-value \\
\hline Right $-\mathrm{P} 1:$ & & & \\
Mean \pm SD & $15.81 \pm 2.13$ & $14.43 \pm 1.58$ & 0.082 \\
Range & $12.2-21.1$ & $12.2-17.3$ & \\
Right-N1: & & & \\
Mean \pm SD & $24.15 \pm 2.02$ & $22.84 \pm 1.32$ & 0.121 \\
Range & $20.7-27.5$ & $20.7-24.2$ & \\
Right amplitude: & & & \\
Mean \pm SD & $57.06 \pm 15.79$ & $65.36 \pm 11.35$ & $0.041^{*}$ \\
Range & $25.1-100.0$ & $50.8-85.3$ & \\
\hline
\end{tabular}

Table 7: Comparison of VEMP latencies P1, N1 and amplitude in left ear for both groups

\begin{tabular}{lccc}
\hline & Study $(\mathrm{n}=30)$ & Control $(\mathrm{n}=10)$ & P-value \\
\hline Right $-\mathrm{P} 1:$ & & & \\
Mean \pm SD & $15.81 \pm 2.13$ & $14.43 \pm 1.58$ & 0.082 \\
Range & $12.2-21.1$ & $12.2-17.3$ & \\
Right-N1: & & & \\
Mean \pm SD & $24.15 \pm 2.02$ & $22.84 \pm 1.32$ & 0.121 \\
Range & $20.7-27.5$ & $20.7-24.2$ & \\
Right amplitude: & & & \\
Mean \pm SD & $57.06 \pm 15.79$ & $65.36 \pm 11.35$ & $0.041^{*}$ \\
Range & $25.1-100.0$ & $50.8-85.3$ & \\
\hline
\end{tabular}

There was a statistically significant difference for the amplitude for both ears, and P1 in the left ear. The asymmetry ratio was calculated for both groups and showed no statistically significant differences between them.

* Caloric testing: 
- In the study group, 23 hearing impaired children $(77 \%)$ had normal response and seven children (23\%) had abnormal response.

* Four children had bilateral weakness.

* Three had unilateral weakness.

- In the control group, all hearing impaired children had normal caloric response.

Table 8: Caloric response for the study group

\begin{tabular}{lcc}
\hline & No. $(\mathrm{n}=30)$ & $\%$ \\
\hline Caloric response: & 23 & 76.7 \\
Normal & 7 & 23.3 \\
Abnormal & & \\
Side of weakness: & 4 & 13.3 \\
Bilateral & 1 & 3.3 \\
Left & 2 & 6.7 \\
Right & & \\
\hline
\end{tabular}

There were no other abnormalities in the caloric response as abnormal fixation, inversion, perversion.

Table 9: comparison between caloric responses in both groups

\begin{tabular}{lccc}
\hline & Patients $(\mathrm{n}=30)$ & Control $(\mathrm{n}=10)$ & P-value \\
\hline R-caloric: & & & \\
Mean \pm SD & $40.83 \pm 22.09$ & $48.80 \pm 14.96$ & 0.260 \\
Range & $0.0-89.0$ & $33.0-88.0$ & \\
L-caloric: & & & \\
Mean \pm SD & $43.97 \pm 24.08$ & $44.70 \pm 15.65$ & 0.755 \\
Range & $4.0-98.0$ & $30.0-71.0$ & \\
\hline
\end{tabular}

Comparison of caloric response (speed of slow phase velocity of the nystagmus) between the study group and the control group reveal no statistically significant difference.

\section{Radiological evaluation:}

- In the study group, 21 children had normal imaging while the last 9 children had abnormal findings, the most common abnormalities was enlarged vestibular aqueduct followed by common cavity then atretic cochlea and lastly dilated lateral SCC vestibule.

- The control groups had normal CT and MRI studies of petrous bone.

Table 10: Radiological evaluation of the study group

\begin{tabular}{lcc}
\hline & No. $(\mathrm{n}=30)$ & $\%$ \\
\hline CT: & 21 & 70 \\
Normal & 4 & 13.3 \\
EVAS & 2 & 6.7 \\
Common cavity & 1 & 3.3 \\
Bilateral dilated lateral & & \\
canal and vestibule & 1 & 3.3 \\
Mondini & 1 & 3.3 \\
Absent left cochlea & & \\
MRI: & 21 & 70 \\
Normal & 4 & 13.3 \\
EVAS & 2 & 6.7 \\
Common cavity & 1 & 3.3 \\
Bilateral dilated lateral & & \\
canal and vestibule & 1 & 3.3 \\
Mondini & 1 & \\
Absent left cochlea with aplastic & & \\
left nerve (detected by MRI only) & & \\
\hline
\end{tabular}

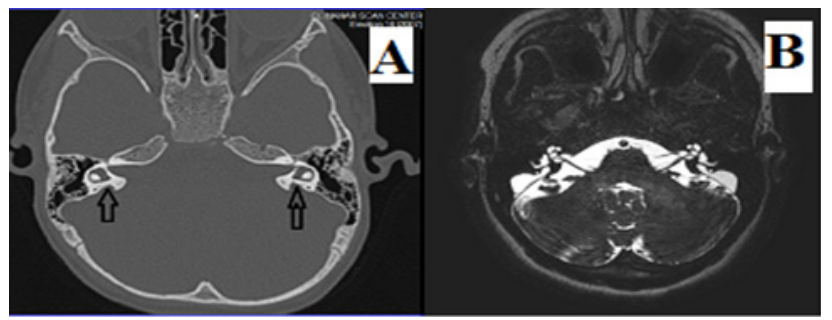

Fig. 1: (A) CT scan showed enlarged vestibular aqueduct measuring $4 \mathrm{~mm}$ in Right ear and $3.5 \mathrm{~mm}$ in Left ear. (B) MRI showed bilateral enlarged vestibular aqueduct.

Relationship between the results VEMP and caloric responses

There were statistically significant differences between the VEMP latencies (right P1, N1 and left P1) and the caloric response. 
Table 11: VEMP results in relationship to caloric response

\begin{tabular}{|c|c|c|c|}
\hline & \multicolumn{2}{|c|}{ Caloric response } & \multirow{2}{*}{$P$-value } \\
\hline & Normal $(n=21)$ & Abnormal (n-9) & \\
\hline \multicolumn{4}{|l|}{ Right-P1: } \\
\hline Mean \pm SD & $15.30 \pm 1.76$ & $18.24 \pm 2.33$ & $0.035^{*}$ \\
\hline Range & $12.2-18.3$ & $16.1-21.1$ & \\
\hline \multicolumn{4}{|l|}{ Right-N1: } \\
\hline Mean \pm SD & $23.73 \pm 1.93$ & $26.15 \pm 1.02$ & $0.023^{*}$ \\
\hline Range & $20.7-27.3$ & $25.1-27.5$ & \\
\hline \multicolumn{4}{|c|}{ Right amplitude: } \\
\hline Mean \pm SD & $56.87 \pm 16.58$ & $57.98 \pm 13.33$ & 0.746 \\
\hline Range & $25.1-100.0$ & $40.1-72.1$ & \\
\hline \multicolumn{4}{|l|}{ Left-P1: } \\
\hline Mean \pm SD & $15.26 \pm 1.27$ & $17.48 \pm 1.30$ & $0.009^{*}$ \\
\hline Range & $12.7-19.1$ & $16.0-19.1$ & \\
\hline \multicolumn{4}{|l|}{ Left-N1: } \\
\hline Mean \pm SD & $23.85 \pm 1.70$ & $25.64 \pm 1.65$ & 0.064 \\
\hline Range & $21.3-28.1$ & $24.1-27.1$ & \\
\hline \multicolumn{4}{|c|}{ Left amplitude: } \\
\hline Mean \pm SD & $54.90 \pm 18.92$ & $65.27 \pm 18.32$ & 0.159 \\
\hline Range & $21.4-106.0$ & $39.3-80.7$ & \\
\hline
\end{tabular}

Correlation between the thresholds of hearing loss and caloric response:

There were significant negative correlation between the threshold of hearing and the caloric response (right $\mathrm{r}=$ -0.552 and for left ear $\mathrm{r}=-0.440$ ) (right $\mathrm{P}=0.002$ and for left $\mathrm{P}=0.015$ ) as shown in the following table.

Table 12: Correlation between caloric test and thresholds of hearing loss

\begin{tabular}{lll}
\hline & r-value & $P$-value \\
\hline Right side & -0.552 & $0.002^{*}$ \\
Left side & -0.440 & $0.015^{*}$ \\
\hline
\end{tabular}

Correlation between degree of hearing loss and motor milestones:

The following table showed the correlation between the degree of hearing loss and the different age of motor milestones in months.
Table 13: Correlation between threshold of hearing loss and motor milestones

\begin{tabular}{lcccc}
\hline \multirow{2}{*}{ Motor } & \multicolumn{4}{c}{ Degree of hearing loss } \\
\cline { 2 - 5 } & \multicolumn{2}{c}{ Right side } & \multicolumn{2}{c}{ Left side } \\
\cline { 2 - 5 } & $\mathrm{r}$-value & $P$-value & $\mathrm{r}$-value & $P$-value \\
\hline Head support & -0.190 & 0.314 & -0.216 & 0.251 \\
Sitting supported & -0.190 & 0.314 & -0.234 & 0.213 \\
Sitting alone & -0.004 & 0.985 & -0.043 & 0.820 \\
Standing supported & 0.105 & 0.583 & 0.033 & 0.861 \\
Standing alone & 0.147 & 0.437 & 0.107 & 0.574 \\
Walking support & 0.148 & 0.436 & 0.107 & 0.575 \\
Walking alone & 0.529 & $0.003 *$ & 0.474 & $0.008^{*}$ \\
\hline
\end{tabular}

There were significant positive correlations between age of "walking alone" and "degree of hearing loss" in both right and left ears $\left(r=0.529 \& \mathrm{P}=0.003^{*}\right)$ and $(r=0.474 \&$ $\left.\mathrm{P}=0.008^{*}\right)$ respectively.

\section{DISCUSSION:}

There were no statistically significant differences for the age or gender for both groups. The difficulty in walking was the most common observation $(80 \%)$ followed by frequent falls $(70 \%)$ then poor balance $(60 \%)$, six patients $(20 \%)$ were complaining of vertiginous attacks and five patients had nystagmus $(16 \%)$

All the motor milestones are significantly higher in comparison to normal. The criterion for normality of the age of acquisition for different motor milestones depend mainly on Long \& Toscano ${ }^{[22]}$; McCarthy ${ }^{[23]}$. In the control group; the age of acquisition of the motor milestones was corresponding with normative data.

In a similar study of $\mathrm{HI}$ children with EVAS, Youssif et $a l:{ }^{[19]}$ studied 39 children ,their age were between 3-12 years, they reported that the average age of walking in children with EVA was 14.6 months , also $50 \%$ of children with EVAS reported at least one of the vestibular symptoms presented in the balance questionnaire and the distribution of the different vestibular symptoms was 6 children with vertigo $(21 \%), 7$ children with poor balance $(25 \%), 4$ children with frequent falls (14\%), one child experience nystagmus $(3.5 \%)$. 
VEMP test was done for both groups: in the control group (10 children, 20 ears) showed that 18 ears (90\%) had VEMP response, while two ears $(10 \%)$ had absent VEMP, this result is in agreement with the previous studies which proved that VEMP waves can be recorded from normal pediatric population ${ }^{[25]}$, young children and school age children $^{[26]}$, and the response rate was $90 \%$ among them ${ }^{[27]}$. While in the study group (30 children, 60 ears), 48 ears (80\%) had VEMP response, and12 ears $(20 \%)$ had absent VEMP (table 5).

There were statistically significant difference for the VEMP amplitude for both ears and the latency (P1) in the left ear. These results were in agreement with Maes et al., ${ }^{[27]}$,Tourtillott, Ferraro et $a l,{ }^{[28]}$, Wang and Young ${ }^{[29]}$, Basta et $a l,,^{[30]}$, and $\mathrm{Wu}$, et $a l,{ }^{[31]}$.

In contrast to this study, some investigators demonstrate different values as in Akin et al. ${ }^{[32]}$, Cheng, Huang, and Young ${ }^{[33]}$, Said ${ }^{[2]}$, and El-Danasoury, El Sirafy et, al. ${ }^{[34]}$. They explained the earlier recording in children might be due to changes in dimensions of the head and neck in younger children which make the recording electrodes closer to the generator sites resulting in shorter latencies.

Absent VEMP in hearing impaired children with delayed motor function in comparison to the control group reflect that the saccule has an important role in the development of static balance. De Kegel et al ${ }^{[35]}$ reported that vestibular dysfunction was present in $30 \%$ to $70 \%$ of $\mathrm{HI}$ children and the prevalence of abnormalities is higher in profound SNHL, they also reported that there were statistically significant differences for the balance results, whereby the HI children with absent VEMPs performed weaker, and showed a larger postural instability due to saccular dysfunction. De Kegel et al ${ }^{[36]}$ stated that the saccule play an important role in the development of static balance.

There were no other abnormalities in the caloric response as abnormal fixation, inversion, perversion. The normal caloric response in all subjects of the control group could be attributed to small number of the group (10 children). There were no statistically significant differences between the slow phase velocities of the caloric test for both groups.

Shambaugh et al, in 1930, collected information from about 5348 children from deaf schools in the US. They found normal vestibular reactions in about $70 \%$ of the children. Also Lindenov (1945) examined 58 deaf-mutes by means of irrigation with water at a temperature of $18 \mathrm{C}$. In his series about $60 \%$ had normal reactions ${ }^{[37]}$

Brookhouser et al, ${ }^{[38]}$ performed caloric tests over 166 children their age between 3 to 19 years with severe-toprofound hearing impairments, $78 \%$ had normal caloric response and $22 \%$ had unilateral or bilateral labyrinthine weakness in response to caloric stimulation.
The results were different to Pajor \& JozefowiczKorczynska $^{[1]}$, who noted abnormal ENG in $88 \%$ of patients (22 ears); in nearly all of them (20 ears), vestibular impairment was of peripheral type. They also reported that in children with SNHL, concomitant damage to vestibular structures is commonly reported. In contradiction to Said ${ }^{[2]}$ who reported that $64 \%$ of her study had horizontal canal dysfunction on caloric testing, either absent or abnormal caloric responses.

CT and MRI studies of petrous bone showed normal radiology for the control group, while in the study group, 21 children $(70 \%)$ had normal imaging and the last 9 children (30\%) had abnormal findings. The most common abnormalities in the study group were EVAS (13\%), followed by two cases of common cavity $(7 \%)$, one case $(3 \%)$ of mondini, one case $(3 \%)$ of absent left cochlea with atretic left nerve and one case $(3 \%)$ of bilateral dilated lateral SCC and vestibule (Table 10).

These results were quite similar to Sennaroğlu studies of inner ear anomalies ${ }^{[39,40]}$, who stated that about $80 \%$ showed normal radiology while the remaining 20\% showed inner ear anomalies, the enlarged vestibular aqueduct represent about $15 \%$ and the common cavity $8 \%$ and mondini $19 \%$. Also the results were similar to the study of Jallu et, al. ${ }^{[41]}$ who found that out of 40 children, 30 children $(72.5 \%)$ had normal radiological scans. Five children $(12.5 \%)$ had enlarged large vestibular aqueduct, and $5 \%$ had cochlear nerve hypoplasia.

In our study the findings of imaging modalities were the same except for the abnormalities of the cochlear nerve which is solely detected by MRI and cannot be visualized by CT. Vila and Lieu ${ }^{[42]}$ reported that although MRI has the advantage of not exposing the child to ionizing radiation, several studies have concluded that $\mathrm{CT}$ is a superior first line diagnostic modality (Haffey et al.$^{[43]} \&$ Licameli and Kenna ${ }^{[44]}$. The benefit of MRI is that some abnormalities such as cochlear nerve aplasia are better visualized, in contrast to $\mathrm{CT}$, where bony abnormalities such as enlarged vestibular aqueduct are more readily detected, both are complementary.

(Table 11) showed statistically significant relationship between the latencies of the VEMP (right P1, N1 and left P1) with the caloric response for those whom had normal response and those with abnormal response in the study group, this can be explained as the lesion affecting the vestibular system affects both the saccule and the lateral semicircular canal. These results were different from Andrade et $a l,{ }^{[45]}$, who found no correlation between VEMPs and caloric, confirming that the two diagnostic techniques are not interchangeable but complementary.

(Table 12) showed the correlation of the thresholds of hearing loss in both ears and the caloric response, there 
was significant negative correlation (right $\mathrm{r}=-0.552$ and for left ear $\mathrm{r}=-0.440$ ) (right $\mathrm{P}=0.002$ and for left $\mathrm{P}=$ 0.015). This might be due to that the higher the thresholds of hearing the more insult and more affection in the vestibular system mainly the lateral canal. Shih, Yu-Ching, et $a l ;{ }^{[46]}$ reported that an abnormal caloric response was significantly associated with a profound hearing loss. Similarly Lavinsky ${ }^{[47]}$ said that the incidence of caloric abnormality is high on deaf people especially the severe to profound degrees.

(Table 13) showed the correlation between the degrees of hearing loss and the different age of motor milestones in months; there were significant positive correlations between "walking alone" and "degree of hearing loss" in both right and left ears $\left(r=0.529 \& \mathrm{P}=0.003^{*}\right)$ and $(\mathrm{r}=0.474$ $\left.\& \mathrm{P}=0.008^{*}\right)$, Inoue et al, ${ }^{[48]}$ reported that as HI children grow older, they progressively begin to use somatosensory and vestibular information until these systems reach full maturity around the age of 10 years.

\section{CONCLUSION AND RECOMMENDATION:}

1-In the study group (30 HI children, 60 ears), 48 ears (80\%) had VEMP response, while 12 ears $(20 \%)$ had absent VEMP and the asymmetry ratio (AR) for the study group was $8.88 \pm 8.98$.

2-There were 23 child (77\%) in the study group had normal caloric response, and seven children $(23 \%)$ had abnormal caloric response, four of them had bilateral weakness, 3 had unilateral weakness (two had right weakness and one child had left weakness).

3- Twenty one children in the study group had normal imaging (70\%) while the last 9 children $(30 \%)$ had abnormal radiology, the most common abnormalities was enlarged vestibular aqueduct (13\%), followed by common cavity $(7 \%)$ and mondini $(3 \%)$.

4- Young children with hearing loss, irrespective of the degree of hearing loss, the vestibular system should be screened, assessed as it may be responsible for comorbidities, such as fine and gross motor difficulties.

5-Vestibular insult may have a major contribution for the delay in the motor function especially those with hearing loss, unfortunately the vestibular investigation are usually overlooked during the evaluation and management of those children.

6-Vestibular evaluation including the caloric test and VEMP are targeting the assessment of different area in the vestibular system: the caloric test for assessment of the lateral canal and the superior vestibular nerve while the VEMP for the saccule and the inferior vestibular nerve.

\section{CONFLICTS OF INTEREST:}

There are no Conflicts of interest.

\section{REFERENCES:}

1. Pajor A, Jozefowicz-korczynsks M. Prognostic factors for vestibular impairment in sensorineural hearing loss. Ear Arch Otorhinolaryngol 2008; 265:403-407.

2. Said E A.F: Clinical balance tests for evaluation of SNHL, The Egyptian Journal of Otolaryngology (2013); 29;189-201.

3. Demer JL, Porter FI, Goldberg J, et al: Dynamic visual acuity with telescopic spectacles: improvement with adaptation. Invest Ophthalmol Vis Sci, 1988; 29:1184-9

4. Admiraal RJ, Huygen PL: Vestibular areflexia as a cause of delayed motor skill development in children with the CHARGE association. Int J Pediatr Otorhinolaryngol $1997 ; 39: 205-22$.

5. Cushing SL, Papsin BC, Rutka JA, et al: Evidence of vestibular and balance dysfunction in children with profound sensorineural hearing loss using cochlear implants. Laryngoscope 2008; 118: 1814-23.

6. Luxon L, Pagarkar W: The dizzy child. Chapter 46. In: Graham JM, Scadding GK, Bull PD, editors. 2008; Pediatric ENT. 1st ed. Germany: SpringerVerlag; 2008. pp. 460-473.

7. Shabana M, I. Dabbous A, O. Hosni N, A. Medhat M,M. , : Can Scoring of symptoms in dizzy children aid in the categorization of the cause of dizziness for accurate referral? ;The Egyptian journal of Otolaryngology 2012: volume 28 number3 september 2012.

8. Tusa R.J., A.A. Saada Jr., J.K. Niparko: Dizziness in childhood, J. Child Neurol. 1997; 9 ; 261-274.

9. Korres S., D. Balatsouras: Diagnostic, pathophysiologic and therapeutic aspects of benign paroxysmal positional vertigo, (2004).

10. Nandi R., Luxon L.M: Development and assessment of the vestibular system in international journal of Audiology 2008; 47:566-577.

11. Gasparini, P., X. Estivill, et al.:"Vestibular and hearing loss in genetic and metabolic disorders." Curr Opin Neurol, 1999; 12(1): 35-9. 
12. Rajendran V, Roy FG. An overview of motor skill performance and balance in hearing impaired children. Ital J Pediatr 2011; 37:33.

13. Zagólski O. Vestibular system in infants with hereditary nonsyndromic deafness. Otology \& Neurotology. 2007;28(8):1053-1055.

14. Eviatar L, Eviatar A. Vertigo in children: differential diagnosis and treatment. Pediatrics 1977;59: 833-8.

15. Balkany TJ, Finkel RS. The dizzy child. Ear Hear 1986; 7 (3): 138-42.

16. Blayney AW, Colman BH. Dizziness in childhood. Clin Otolaryngol 1984; 9: 77-85.

17. D'Agostino R, Tarantino V, Melagrana A,Taborelli G. Otoneurologic evaluation of child vertigo. Int $\mathrm{J}$ Pediatr Otorhinolaryngol 1997:40:133-9.

18. Valente M, Devin L. McCaslin, : Vestibular Disorders and Evaluation of the Pediatric Patient: March 2011, Vol. 16, 12-15. doi:10.1044.

19. Yousef M A, Robert W. Keith, Fawen Zhang, David Brown; Vestibular Evoked Myogenic Potential (VEMP) in children with Enlarged Vestibular Aqueduct (EVA) 2012.

20. Soliman S. Development and standardization of Arabic language central auditory tests. Unpublished Doctorate thesis. (1985); Ain Shams University, Cairo, Egypt.

21. Soliman SM. Speech discrimination audiometry using Arabic Kindergarten Phonetically Balanced (PB-KG) words. Ain Shams Med J;(1976); 27; 27-30.

22. Long, T., \& Toscano, K: Handbook of pedatric physical therapy.2002, Philadelphia, PA: Lippincott, Williams, \& Wilkins.

23. McCarthy MS, Jessica L; Developmental Milestones and Feeding; Feeding Infants \& Toddlers Strategies for Safe, Stress-free Mealtimes Mosaic Childhood Project, Inc 2006.

24. Clark, J. G. (1981). Uses and abuses of hearing loss classification. 23, 493-500.

25. Erbek, S., Erbek, S. S., Gokmen, Z., Ozkiraz, S., Tarcan, A., \& Ozluoglu, L. N.; Clinical application of vestibular evoked myogenic potentials in healthy newborns. [Research Support, Non-U.S. Gov't]. Int J Pediatr Otorhinolaryngol, 2007:71(8), 1181-1185.
26. Kelsch TA, Schaefer LA, Esquivel CR: Vestibular evoked myogenic potentials in young children: test parameters and normative data. Laryngoscope 2006; 116: 895-900.

27. Maes, L., Dhooge, I., D'Haenens, W., Bockstael, A., Keppler, H., Philips, B. Vinck, B. M: The effect of age on the sinusoidal harmonic acceleration test, pseudorandom rotation test, velocity step test, caloric test, and vestibular-evoked myogenic potential test [Research Support, Non-U.S. Gov't]. Ear Hear, 2010; 31(1), 84-94.

28. Tourtillott, B. M., Ferraro, J. A., Bani-Ahmed, A., Almquist, E., \& Deshpande, N.; Age-related changes in vestibular evoked myogenic potentials using a modified blood pressure manometer feedback method.[Research Support, Non-U.S. Gov't]. 92010) Am J Audiol, 19(2), 100-108.

29. Wang, S. J., \& Young, Y. H.; Vestibular evoked myogenic potentials using simultaneous binaural acoustic stimulation. [Research Support, Non-U.S. Gov't]. Hear Res, (2003):185(1-2), 43-48.

30. Basta, D., Todt, I., \& Ernst, A; Normative data for P1/N1-latencies of vestibular evoked myogenic potentials induced by air- or bone-conducted tone bursts. [Research Support, Non-U.S. Gov't]. Clin Neurophysiol, (2005);116(9),2216-2219.

31. Wu, H.J., Shiao a.s, Yang, Y,L,\& Lee G.S,.; Comparison of short tone burst evoked and click evoked vestibular myogenic potential (comparative study) J China Med Assoc. (2007) 70(4),159-163.

32. Akin, F. W., Murnane, O. D., \& Proffitt, T. M. ; The effects of click and tone- burst stimulus parameters on the vestibular evoked myogenic potential (VEMP).[Comparative Study Research Support, Non-U.S. Gov't Research Support, U.S. Gov't, NonP.H.S.]. J Am Acad Audiol, (2003); 14(9), 500-509; quiz 534-505.

33. Cheng, P. W., Huang, T. W., \& Young, Y. H; The influence of clicks versus short tone bursts on the vestibular evoked myogenic potentials. [Research Support, Non-U.S. Gov't]. Ear Hear, (2003) 24(3), 195-197.

34. El-Danasoury I. El Sirafy G., Taha H., Hegazy S.,: Vestibular evoked myogenic potentials (VEMPs) in young children: Test parameters and normative data: Egyptian Journal of Ear, Nose, Throat and Allied Sciences: (2015): VOL16.Issu1. page 81-85. 
35. De Kegel A, Dhooge I, Cambier D, Baetens T, Palmans T,Van Waelvelde H.: Test-retest reliability of the assessment of postural stability in typically developing children and in hearing impaired children gait \& posture. J Gait Posture 2011; 33:679-685.

36. De Kegel A, Leen Maes, Tina Baetens, Ingeborg Dhooge, Hilde Van Waelvelde: The Influence of a Vestibular Dysfunction on the Motor Development of Hearing-Impaired Children; Laryngoscope: 2012.

37. Sharon Lynn: Relationship between sensorineural hearing loss and vestibular and balance function in children, Institute of Medical Science, University of Toronto 2008

38. Brookhouser, Patrick E. David G, Kathryn A. Beauchaine: Vestibular Findings in the Deaf and Hard of Hearing :SAGE JOUR, Vol 1982: 90, Issue 6 .

39. Sennaroglu L, Saatci I. A new classification for cochleovestibular malformations. Laryngoscope 2002; 112(12):2230-2241.

40. Sennaroğlu and Bajin. Classification and Current Management of Inner Ear Malformations 2017.

41. Jallu, Hamid, Jehangir, Waqar, Rafiq, Pampori: Imaging Evaluation of Pediatric Sensorineural Hearing Loss in Potential Candidates for Cochlear Implantation: Indian J Otolaryngol Head Neck Surg: 2015: (Oct-Dec 2015) 67(4):341-346; DOI 10.1007/ s12070-015-0819-6.
42. Vila PM, Lieu JE; Asymmetric and unilateral hearing loss in children. Cell and tissue research: 2015 Jul;361(1):271-8. doi: 10.1007/s00441-015-2208-6. Epub 2015 May 26.

43. Haffey T, Fowler N, Anne S: Evaluation of unilateral sensorineural hearing loss in the pediatric patient. Int J Pediatr Otorhinolaryngol; (2013); 77:955-958.

44. Licameli G, Kenna MA: Is computed tomography (CT) or magnetic resonance imaging (MRI) more useful in the evaluation of pediatric sensorineural hearing loss? Laryngoscope; (2010); 120:23582359 .

45. Andrade et, al.: Correlation between bithermal caloric test results and vestibular evoked myogenic potentials (VEMPs) in normal subjects. Eur Arch Otorhinolaryngol, 2013; 270:1623-1628.

46. Shih, Cheng-Ping ; Yu-Ching Chou, ; Hsin-Chien Chen, ,; Jih-Chin Lee, ; Yueng-Hsiang Chu,; ChihHung Wang, : Analysis of caloric test response in sudden hearing loss : ENT journal: 2017 march18.

47. Lavinsky L; Estudo da função labiríntica em crianças com hipoacusia severa e profunda. Rev. HCPA, 2005, 10(1):14-26

48. Inoue, A., Iwasaki, S., Ushio, M., Chihara, Y., Fujimoto, C., Egami, N. and Yamasoba, T: Effect of Vestibular Dysfunction on the Development of Gross Motor Function in Children with Profound Hearing Loss. Audiology \& Neurotology 2013; 18, 143-151. http://dx.doi.org/ 10.1159/000346344. 